SHORT COMMUNICATION

\title{
Comparative Evaluation of Therapeutic Modules for Treatment of Parvoviral Gastroenteritis in Dogs
}

\author{
Rajiv Kumar1, Bipin Kumar ${ }^{1 *}$, Sushil Kumar ${ }^{1}$ and Archana Kumari ${ }^{2}$ \\ ${ }^{1}$ Department of Veterinary Medicine, BASU, Patna, Bihar, INDIA \\ ${ }^{2}$ Department of Veterinary Surgery ERadiology, BASU, Patna, Bihar, INDIA \\ *Corresponding author: B Kumar; E-mail:drvetbipin@rediffmail.com
}

Received: 22 April, 2020

Revised: 08 July, 2020

Accepted: 16 July, 2020

\begin{abstract}
The present study was conducted on 18 clinically affected dogs of different breeds and age. All the dogs were divided into three groups A, B and C consisting of 6 animals in each one. Group A dogs were given standard therapy. In group B dogs were treated with immune plasma besides standard therapy. In group $\mathrm{C}$ dogs were treated with amino acid infusion besides standard therapy. In group A 3 out of 6 dogs (50\%) showed complete recovery from dehydration and other clinical signs on day 4 post-treatments, while remaining 3 dogs $(50 \%)$ recovered on day 5 post-treatments. In group B 4 dogs $(66.66 \%)$ recovered completely from dehydration and other clinical signs on day 3 post-treatment, while remaining dogs $(33.33 \%)$ recovered on day 4 post-treatment. In group C $5 \operatorname{dogs}(83.33 \%)$ recovered completely from dehydration and other clinical sign on day 2 post-treatment, while remaining dogs $(16.66 \%)$ recovered on day 3 post-treatment. It has been concluded that among various treatment groups, group $\mathrm{C}$ (Amino acid + Supportive therapy) was found to be superior as all six (6) dogs recovered day 3 post-treatment.
\end{abstract}

\section{HIGHLIGHTS}

(0 Three types of therapeutic module were evaluated for the treatment.

(- Treatment with immune plasma and supportive therapy was found to be good.

(o However, amino acid treated group was most effective.

Keywords: Parvovirus, gastroenteritis, dog, amino acid, dehydration

Canine Parvovirus infection is highly fatal infectious disease and caused by type- 2 canine parvovirus characterized by gastroenteritis or hemorrhagic gastroenteritis with vomition and fever. Canine parvovirus is of two types (CPV-1 and CPV-2). The virus was classified on the basis of position of amino acid. After the first report of this disease in India, its prevalence has been reported to increased in recent past (Banja et al. 2002) in unvaccinated dogs. The canine parvovirus belongs to genus Parvovirus and Parvoviridae family (Berns 1990, and Touihri et al. 2009). The genome is single stranded DNA having size of $5.2 \mathrm{~Kb}$ (Perez et al., 2007). The Canine parvovirus infection causes mortality up to $10 \%$ and a high morbidity up to 100\% (Appel et al. 1978). Maximum prevalence of canine parvo virus infection is seen young puppies between 1-4 months of age and less prevalence is recorded in adult dogs. Most adult dogs are immune to the disease either via natural infection or immunization. The clinical symptoms associated with parvovirus infections are gastroenteritis and myocarditis. But the GI tract involvement leads to severe damage and caused by CPV-2 resulting in bloody diarrhoea $\&$ secondary bacterial infections due to immune suppression. The virus kills the host either one of the two ways- diarrhoea \& vomition, which lead to extreme fluid loss and dehydration culminated with shock and death. The second form of CPV-2 infection is cardiac syndrome

How to cite this article: Kumar, R., Kumar, B., Kumar, S. and Kumari, A. (2020). Comparative evaluation of therapeutic modules for treatment of parvoviral gastroenteritis in dogs. J. Anim. Res., 10(4): 673-676.

Source of Support: None; Conflict of Interest: None 
or myocarditis which can affect puppies under 3 months of age (Appel et al., 1979) leading to the sudden death in young pups (Mochizuki et al. 1996). Acute heart failure with respiratory distress occurs in pups between 4 \& 8 weeks of age. Subacute heart failure occurs in older pups usually 8 weeks or above. Although a lot of work has been conducted in parvo virus infection, pertaining to their epidemiology, diagnosis, treatment and control, but still there is high mortality in clinical cases. Considering the importance of parvo virus infection and its associated mortality, the present therapeutic modules has been tried to save the dogs suffering from clinical parvo viral infection.

All the canine parvo virus positive cases, were randomly divided into three group viz. group A, group B and group $\mathrm{C}$ each consisting of 6 dogs. Another 6 apparently healthy dogs were placed in D-group as healthy control (altogether there were four groups). Group A dogs were treated with Ringer lactate (RL) @ 30-40 ml/kg b.wt., BID I/V DNS (a) 20-30 ml/kg b.wt., BID, Antibiotic-(Cefriaxone + Tazobactum@15-25 mg/kg b.wt. BID Ranitidine@2-4 mg/kg Botropose@0.5-1 ml SOS B-Complex@1 ml I/V Antiemetic- Ondem @ 1 ml I/M, Group B dogs were treated with immune plasma besides group A therapy and group $\mathrm{C}$ dogs were treated with amino acid besides group B therapy. Group-D, dogs were not given any therapy. To justify the changes in pre and post-treatment status the following biochemical parameters were estimated viz. total serum protein (TSP), alkaline phosphatase (ALP), Albumin: globulin ratio (A: $\mathrm{G}$ ) by using kits (Coral clinical systems Goa, India). Besides alteration in biochemical parameters the other clinical manifestation were also included in the evaluation of recovery viz changes in consistency of faeces, discontinuation of vomition, alertness, restoration of skin tonicity etc.

In group A dogs, administration of Ringer's Lactate (RL) (a) 30-40 ml/kg IV, DNS @ 20-30 ml/kg IV, Antibiotic (cefriaxone + Tazobactum) @ 15-25 mg/kg BID IV, Ranitidine@ 2-4 mg/kg OD IV, Botropose@ 0.5-1 ml SOS IV, CB12@1 ml IV and Antiemetic@1 mg/ $\mathrm{kg}$ IV. 3 out of 6 dogs (50\%) showed complete recovery from dehydration and other clinical signs on day 4 posttreatments, while remaining 3 dogs $(50 \%)$ recovered on day 5 post-treatments. In CPV infection due to severe diarrhoea and vomiting, electrolytes are lost in high quantity in the faeces and vomitus and total body sodium, chloride and potassium are depleted (Ramprabhu, 2002). In the ionized form, calcium is essential for the functional mechanism of the clotting of blood, normal cardiac function, and regulation of neuromuscular irritability (Sutin and Paul, 2012). In group B administration of Immune plasma@2.5 $\mathrm{ml} / \mathrm{kg}$ and supportive therapy 4 dogs $(66.66 \%)$ recovered completely from dehydration and other clinical signs on day 3 post-treatment, while remaining dogs (33.33\%) recovered on day 4 post-treatment. Immune plasma therapy proves beneficial, especially when the total protein levels drop below $3.5 \mathrm{~g} / \mathrm{dl}$. A plasma transfusion serves to both help in restoration of plasma oncotic pressure and to provide a source of immunoglobulin's (Mazzaferro et al. 2002). In group C administration of Amino acid @ $1.2 \mathrm{ml} /$ $\mathrm{kg} / \mathrm{h}$ and supportive therapy $5 \mathrm{dogs}(83.33 \%)$ recovered completely from dehydration and other clinical sign on day 2 post-treatment, while remaining dogs (16.66\%) recovered on day 3 post-treatment. administration of amino acids increases the plasma insulin concentration (Yamaoka et al. 2006).

Thus, in present study among various treatment groups, group C (Amino acid + Supportive therapy) was found to be superior as all six (6) dogs recovered day 3 posttreatment. However, the groups B and groups A showed comparable improvement on day 4 post-treatment and day 5 post-treatment respectively, hence amongst these three groups; group $\mathrm{C}$ was considered as superior than group B and group $A$ on the basis of overall percentage recovery and improvement of number of dogs. The total serum protein $(\mathrm{g} / \mathrm{dl})$ mean value of pre-treatment of infected groups A, $\mathrm{B}$, and $\mathrm{C}$ was $5.28 \pm 0.10,5.58 \pm 0.09$ and $5.75 \pm 0.13$ $\mathrm{g} / \mathrm{dl}$ respectively, which was significantly lower $(\mathrm{p} \leq 0.05)$ than the control group (Table 1). After treatment the mean value TSP $(\mathrm{g} / \mathrm{dl})$ group A, B and C were $7.13 \pm 0.02,7.25$ $\pm 0.07,7.25 \pm 0.05$ respectively. Although, it was higher than the control group but it was non-significant $(p \leq 0.05)$. Similar findings were reported by Ramprabhu et al. (2002) and Dharmadheeranet al. (2003). Hypoproteinemia might be due to the leakage of serum protein through damaged capillaries of the villi of intestine and also due to less absorption through the damaged villi (Biswas et al. 2005).

The ALP value of infected groups were significantly $(p \leq 0.05)$ higher in comparison to healthy control group D. The mean values of infected group A, B and C were 197.27 $\pm 16.80,276.65 \pm 20.00$ and $256.07 \pm 14.73$ respectively (Table 1). which were high in comparison to healthy group $170.60 \pm 36$. Significantly increase in ALP $276.65 \pm 20.00$ 
Table 1: Mean \pm SE of different biochemical parameters

\begin{tabular}{lllllll}
\hline \multirow{2}{*}{ Group } & \multicolumn{3}{c}{ Pre treatment } & \multicolumn{3}{c}{ Post treatment } \\
\cline { 2 - 8 } & $\mathbf{A L P}(\mathbf{I U} / \mathbf{L})$ & $\mathbf{T S P}(\mathrm{g} / \mathbf{d l})$ & $\mathbf{A} / \mathbf{G}$ ratio & ALP $(\mathbf{I U} / \mathbf{L})$ & TSP $(\mathbf{g} / \mathbf{d l})$ & $\mathbf{A} / \mathbf{G}$ ratio \\
\hline $\mathrm{A}$ & $197.27^{\mathrm{bc}} \pm 16.80$ & $5.28^{\mathrm{a}} \pm 0.10$ & $0.82^{\mathrm{a}} \pm 0.05$ & $173.08^{\mathrm{b}} \pm 7.76$ & $7.13^{\mathrm{b}} \pm 0.02$ & $1.04^{\mathrm{b}} \pm 0.01$ \\
$\mathrm{~B}$ & $276.65^{\mathrm{c}} \pm 20.00$ & $5.58^{\mathrm{ab}} \pm 0.09$ & $0.75^{\mathrm{a}} \pm 0.05$ & $191.46^{\mathrm{c}} \pm 5.16$ & $7.25^{\mathrm{b}} \pm 0.07$ & $1.04^{\mathrm{b}} \pm 0.01$ \\
$\mathrm{C}$ & $256.07^{\mathrm{c}} \pm 14.73$ & $5.75^{\mathrm{b}} \pm 0.13$ & $0.71^{\mathrm{a}} \pm 0.03$ & $197.97^{\mathrm{bc}} \pm 5.37$ & $7.25^{\mathrm{b}} \pm 0.05$ & $1.16^{\mathrm{b}} \pm 0.06$ \\
$\mathrm{D}$ (control) & $170.60^{\mathrm{a}} \pm 0.36$ & $6.50^{\mathrm{b}} \pm 0.10$ & $1.05^{\mathrm{b}} \pm 0.03$ & $170.60^{\mathrm{a}} \pm 0.36$ & $6.50^{\mathrm{b}} \pm 0.10$ & $1.05^{\mathrm{b}} \pm 0.03$ \\
\hline
\end{tabular}

*Mean \pm SE with different superscript differs significantly $(\mathrm{p}<0.05)$.

IU/L may occur as a result of hepatic hypoxia secondary to severe hypovolumia or the absorption of toxic substances due to loss of the gut barrier. The mean serum $\mathrm{A} / \mathrm{G}$ ratio levels of dogs infected with parvovirus group $\mathrm{A}, \mathrm{B}$ and $\mathrm{C}$ was $0.82 \pm 0.05,0.75 \pm 0.05$ and $0.71 \pm 0.03$ respectively, which was significantly $(\mathrm{p} \leq 0.05)$ lower than control groups (Table 1). After treatment the mean value of $\mathrm{A} / \mathrm{G}$ ratio $(\mathrm{g} / \mathrm{dl})$ in group $\mathrm{A}, \mathrm{B}$, and $\mathrm{C}$ were $1.04 \pm 0.01$, $1.04 \pm 0.01$ and $1.16 \pm 0.06$ respectively. However, nonsignificant ( $\mathrm{p} \geq 0.05$ ) increases was noticed as compared to control group. The present findings are in agreement with Ramprabhuet al. (2002), Sharma et al. (2003), Biswas et al. (2005), Baruah et al. (2007) and Sagar et al. (2008) who also reported the decrease in albumin and increase in globulin in hepatobiliary disorders lead to decrease in Albumin: Globulin (A: G) ratio.

\section{CONCLUSION}

Hence, from present study it can be concluded that the above described biochemical parameters may be considered as prognostic marker in the treatment of clinical parvovirus infection in dogs and the best therapeutic module for the treatment of canine parvoviral gastroentritis. Amino acid infusion@1.2 ml/kg/h with other supportive therapy the recovery rate was found to be highest with shortest time.

\section{ACKNOWLEDGEMENTS}

The authors are thankful to Director Research, Bihar Animal Sciences University, Patna for providing facility and necessary help.

\section{REFERENCES}

Appel, M.J.G., Cooper, B.J., Greisen, H. and Carmichael, L.E.
1978. Status report canineviral enteritis. J. Am. Vet. Med. Assoc., 173: 1516-1518.

Appel, M.J.G., Scott. F.W. and Carmichael, L.E. 1979. Isolation and immunization studies of a canine parvo like virus from dogs with haemorrhagic enteritis. Vet. Res. 105: 156-159.

Banja B.K., Sahoo N., Das P.K. and Ray S.K. 2002. Clinicotherapeutic aspects of gastroenteritis in dogs. Indian Vet. J., 19(5): 837-840.

Baruah, M.S., Hazarika, G.C. and Phukan, A. 2007. Clinicobiochemical profile in Canine parvoviral infection. Indian $J$. Vet. Med., 84: 212-214.

Berns, K.I. 1990. Parvoviridae and their replication. Virology, 2: $1743-1763$.

Biswas, S., Chakravorty, D. and Pradhan, N.R. 2005. Clinical and haemato biochemical changes in Parvovirus infection in dogs. Indian J. Vet. Med., 25(1): 16-18.

Dharmadheeran J.S., Kumar M. and Shukla S.K. 2003. Monitoring of haemato-biochemical parameters in experimental canine parvovirus infection. Indian J. Vet. Med., 23(1): 91-93.

Mazzaferro, E.M., Rudloff, E. and Kirby, R. 2002. The role of albumin replacement in the critically ill veterinary patient. $J$. Vet. Emer. Crit. Care, 12(2): 113-124.

Mochizuki, M., Horiuchi, M., Hiragi, H., San, Gabriel, M. C., Yasuda, N. and Uno, T. 1996. Isolation of canine parvo virus from a cat manifesting clinical signs of feline panleucopenia. J. Clin. Microbiol., 34: 2101-2105.

Perez, L., Franca, V., Romeo, L., Maya, I., Lopez, M. and Hernadez. 2007. First detection of canine parvo virus type two 2c in South America. Vet. Microbiol., 124: 147-152.

Ramprabhu, R., Prathaban, S., Nambi, A.P. and Dhanpal, P. 2002. Hemorrhagic gastroenteritis in dogs- A clinical profile. Indian Vet. J., 79: 374-376.

Sagar, A.K., Roy, S. and Roy, M. 2008. Clinico, haematobiochemical changes and diagnosis of canine parvoviral enteritis. Intas. Polivet., 9(2): 262-265. 
Sharma, S, Dhar, P., Thakur, A., Sharma, V. and Sharma, M. 2003. Clinical and therapeutic studies on canine gastroenteritis. M.V.Sc. Thesis, Department of Veterinary Medicine, CSK Himachal Pradesh Krishi Vishvavidyalaya, Palampur, India.

Sutin, K.M. and Paul, L.M. 2012. The ICU book, $3^{\text {rd }}$ Edn., Lippincott William and Wilkins, pp. 1088.

Touihri, L., Bouzid, I., Daoud, R., Desario, C., Founa, E. L., Goulli, A., Decaro, N., Ghorbel, A., Buonavoglia, C., and Bahloul, C. 2009. Molecular characterization of canine parvovirus-2 variants circulating in Tunisia. Virus Genes, $\mathbf{3 8}$ : 249-258.
Yamaoka, I., Doi, M. and Nakayama, M. 2006. Intravenous administration of amino acids during anesthesia stimulates muscle protein synthesis and heat accumulation in the body. Am. J. Physiol. Endocrinol. Metab., 290: 882-888. 